\title{
Biologic Sample Preservation Procedure
}

National Cancer Institute

\section{Source}

National Cancer Institute. Biologic Sample Preservation Procedure. NCI Thesaurus. Code C64262.

Procedures utilized to save organic substances from decay. Some preservation procedures are meant to maintain cells, tissues, or organisms in a viable state. 